\section{TRANSESOPHAGEAL DOPPLER DEVICES: A TECHNICAL REVIEW}

Patrick Schober MD, Stephan A. Loer MD, PhD, MSc and Lothar A. Schwarte MD, PhD
From the Department of Anesthesiology, VU University Medical Center, De Boelelaan 1117, 1007 MB Amsterdam, The Netherlands.

Received 3 August 2009. Accepted for publication 30 September 2009.

Address correspondence to P. Schober MD, Department of Anesthesiology, VU University Medical Center, De Boelelaan 1117, 1007 MB Amsterdam, The Netherlands.

E-mail: P.Schober@vumc.nl
Schober P, Loer SA, Schwarte LA. Transesophageal Doppler devices: a technical review.

J Clin Monit Comput 2009; 23:391-401

ABSTRACT. Monitoring of aortic blood flow, conducting large portions of the cardiac output (CO), allows conclusions on the global hemodynamic status of patients. For this purpose, transesophageal Doppler (TED) devices have been developed, which interrogate the descending aorta and calculate aortic blood flow velocity using the Doppler principle. The recorded velocity-time curve can be used to estimate $\mathrm{CO}$ as well other advanced hemodynamic parameters such as preload, afterload and myocardial contractility. Clinical studies in perioperative patients have demonstrated a reduced postoperative morbidity and shorter length of hospital stay when TED is used to guide fluid management. However, several assumptions are needed to translate the measured Doppler frequency shift to hemodynamic variables and discrepancies between the assumed and the actual condition may introduce a considerable risk for erroneous calculations. A correct interpretation of the displayed parameters requires profound knowledge on the technical basis of this method as well as its technical limitations. Our review focuses on these technical aspects which the clinician should be familiar with to allow proper use of TED monitoring devices.

KEY WORDS. Doppler, ultrasound, cardiac output, stroke volume, hemodynamic monitoring.

\section{INTRODUCTION}

Diagnostic ultrasound is increasingly used in anesthesiology and intensive care medicine. On the one hand, B-mode ultrasound allows clinicians to identify anatomical structures and can thus facilitate vascular puncture $[1,2]$ or regional anesthesia [3, 4]. On the other hand, Doppler ultrasound is used to assess blood flow within vessels to monitor regional perfusion of different organs such as the brain, kidneys or uterus [5-9]. Measurements of blood flow in the aorta, conducting large portions of the cardiac output $(\mathrm{CO})$, allow global hemodynamic monitoring. For this purpose, Transesophageal Doppler (TED) devices have been developed, which interrogate the descending aortic blood flow and permit estimations of $\mathrm{CO}$, preload, afterload and myocardial contractility. In general, TED might be a less invasive alternative to other monitoring techniques such as thermodilution using a pulmonary artery catheter. A major advantage of TED is that it allows extended monitoring and facilitates hemodynamic optimization in patients in whom advanced 
hemodynamic parameters such as $\mathrm{CO}$ would otherwise not be monitored. Compared to conventional clinical assessment, fluid management guided by TED to optimize stroke volume has been shown to improve patient outcome and to reduce the length of hospital stay [10-19], suggesting that this technique can be a valuable supplement to current standard hemodynamic monitoring.

Early TED devices were complex to operate which prevented a widespread use. More recently, modern, userfriendly TED devices have been developed making this technique suitable for routine clinical use. The growing interest in TED monitoring is reflected by the publication of recent review articles, which mainly focus on clinical aspects of the technology [20, 21]. However, correct interpretations of the displayed parameters require a thorough understanding of the technical basis and the assumptions which are required to translate the measured Doppler frequency shift into hemodynamic parameters. Therefore, this non-systematic review article focuses on technical aspects and limitations which the clinician needs to consider to allow rational use of the technology.

\section{THE DOPPLER EFFECT}

An apparent change in the frequency of a wave noted by an observer moving relative to the source of the wave (Figure 1) was first proposed by the Austrian physicist Christian Andreas Doppler (1803-1853) in 1842 at a meeting of the Royal Bohemian Society of Sciences in Prague [22]. Doppler compared this effect, which has subsequently been termed the "Doppler Effect", with a ship which crosses waves more frequently when heading against the waves than when moving in the same direction as the waves. The Dutch scientist Buys Ballot (18171890), actually a critic of Doppler aiming to disprove his theory, supplied first empiric evidence of the Doppler Effect on the railway between Amsterdam and Utrecht (the Netherlands) [23, 24]. Since accurate measurement of wavelengths was not possible at that time, musicians with a skilled sense of hearing were positioned at the rails and asked to rate the pitch of a brass instrument played on the train and vice versa. Indeed, the perceived pitch appeared higher as the actually played tone whenever the instrument and the musician approached and lower as they departed from each other [23, 24].

Waves reflected by moving objects also undergo a Doppler frequency shift. The total Doppler effect results from motion of the wave emitter, the reflecting object and the receiver. The discrepancy between actual and noted frequency, i.e. the frequency shift, is directly pro-

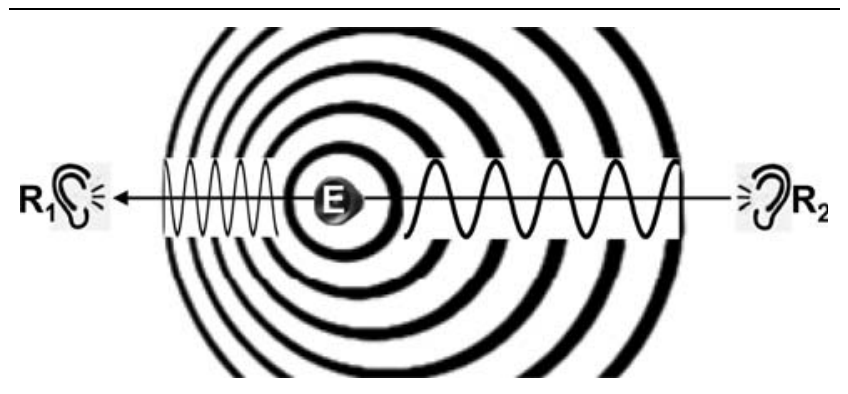

Fig. 1. The Doppler effect describes an apparent change in the frequency of a wave when the emitter of the wave and the receiver move relative to each other. The perceived frequency is higher than the actually emitted frequency when the emitter $(E)$ approaches the receiver $\left(R_{1}\right)$ and lower when the emitter moves away from the receiver $\left(R_{2}\right)$. The frequency shift is proportional to the relative velocity between emitter and receiver.

portional to the relative velocity between emitter and receiver. Therefore, if the emitter or receiver are stationary or move with a known speed and direction, the velocity and direction of the moving object can be determined. Nowadays, this principle is widely used in radar systems, such as in air traffic control radar, weather radars, and police speed guns. In medicine, Doppler sonography is used by applying the Doppler principle to ultrasound technology.

\section{TRANSESOPHAGEAL DOPPLER SONOGRAPHY}

Enhancing ultrasound with measurements of Doppler frequency shifts allows us to determine blood flow velocity. Herein, ultrasound emitted by a transducer is reflected by moving red blood cells (Figure 2) [25]. Basically, two types of Doppler Sonography can be distinguished: in continuous wave Doppler (CWD), two adjacent transducers couple continuous transmission of ultrasound with continuous reception of reflected waves, whereas Pulsed wave Doppler (PWD) only uses one transducer which intermittently transmits and receives [26]. The physical characteristics of the emitted ultrasound waves depend on their frequencies, which usually vary between 1 and $10 \mathrm{MHz}$ for medical purposes. Tissue penetration depth is inversely related to the frequency whereas the intensity of the reflected sound is proportional to the fourth power of the frequency [26, 27]. Therefore, the "optimal" frequency for each application depends on the depth of the structure to be examined and represents the best compromise between signal strength and tissue penetration.

The blood flow velocity $(v)$ is directly proportional to the frequency shift $(\Delta f)$ and can be calculated by the standard Doppler equation [26, 28, 29]: 


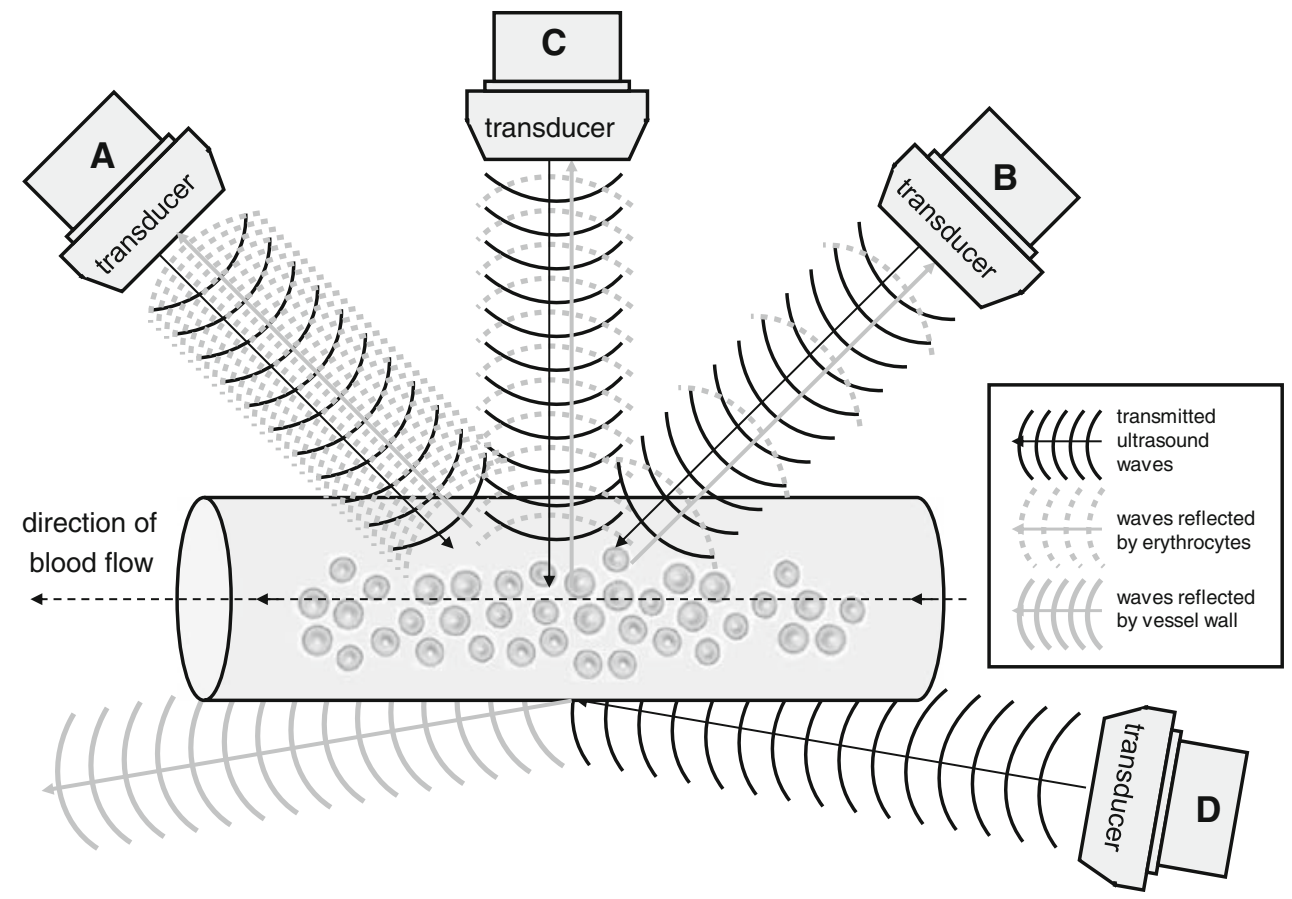

Fig. 2. Doppler ultrasound transducers directed towards a blood vessel at different angles. When the blood flow is directed towards the transducer (A), the frequency of the reflected ultrasound waves increases as compared to the transmitted frequency. In contrast, blood flow away from the transducer (B) is associated with a decrease in reflected ultrasound frequency. Ultrasound insonated at $90^{\circ}(C)$ does not undergo any frequency shift, because erythrocytes neither move towards nor away from the transducer. When the vessel is insonated at very shallow angles (D), a major proportion of the waves is reflected by the vessel wall and does not reach the lumen.

$$
v=\frac{\Delta f \times c}{2 f_{\mathrm{T}} \times \cos \theta}
$$

where $c$ is the velocity of the ultrasound waves in body tissue (average $1,540 \mathrm{~m} \mathrm{~s}^{-1}$ in soft tissue [28]) and $f_{\mathrm{T}}$ the emitted frequency. The cosine of the angle between Doppler beam and blood flow $(\cos \theta)$ is a correction factor needed to adjust for the angle of insonation. Maximal Doppler shift is obtained when the erythrocytes move directly towards or away from the receiver in a straight line $\left(0^{\circ}\right)$ whereas ultrasound insonated at $90^{\circ}$ does not undergo any Doppler shift because no component of the flow is parallel to the ultrasound beam (Figure 2). The cosine changes slowly at shallow angles due to the nonlinear character of the cosine function but rapidly changes at increasing angles. Therefore deviations of the actual from the assumed angle of insonation will result only in a moderate error in flow velocity calculation with shallow angles but becomes unacceptably high with angles exceeding $\sim 60^{\circ}$ (Figure 3 ). Thus, the angle of insonation should ideally be as close to $0^{\circ}$ as possible. However, as the ultrasound beam passes through the wall of the vessel, a certain proportion is reflected and does not reach the lumen. The extent of reflection is higher at shallow angles, technically precluding very shallow angles due to nearly complete wave reflection (Figure 2). Thus, insonation angles between $30^{\circ}$ and $60^{\circ}$ are considered useful [26].

Franklin et al. are credited for performing first prototypical blood flow measurements with Doppler sonography in 1961 by clamping two transducers on the aorta of a dog [30], however, in fact Satomura had already published an article in a Japanese journal about Doppler flow measurements in humans 2 years earlier [31]. Shortly after these pioneer articles, non-invasive transcutaneous transducers were developed for clinical use [32, 33]. In subsequent studies, the ultrasound beam was directed from an intercostal space or suprasternal notch towards the aortic arch or ascending aorta, allowing non-invasive determinations of aortic blood flow in humans [34, 35]. Continuous monitoring was, however, complicated because it was hardly possible to fix an external transducer in place and to avoid changes in insonation angle or loss of the signal. In contrast, esophageal placement of the probe, first described by Side and Gosling [36], allows to keep it in place in close proximity to the descending aorta. The esophagus and descending aorta run almost parallel at the mid-thoracic level. Therefore, the insonation angle is 

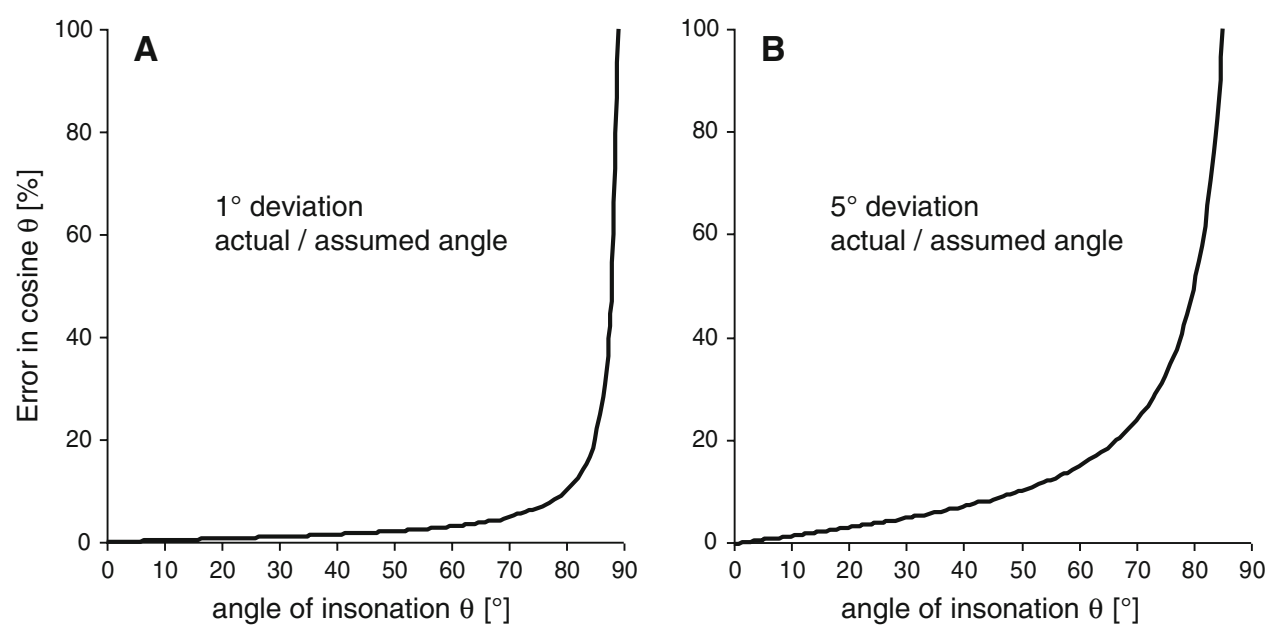

Fig. 3. Percent error in cosine of the angle of insonation $(\theta)$ resulting from $1^{\circ}(A)$ and $5^{\circ}(B)$ deviation in the actual from the assumed angle. Note that the error is negligible or moderate at shallow angles but markedly increases at higher angles.

approximately the same as that between the probe and the transducer if the transducer is mounted to the probe in a fixed angle [37-39], allowing interrogation of descending aortic blood flow with a stable, known angle of insonation. This technique of transesophageal Doppler measurements of aortic blood flow velocity has subsequently been further refined by other investigators [37, 39-45], and several commercial devices have been developed. Most of these devices, however, are no longer marketed as they turned out to be complex and not user friendly, became technically outdated or were bought up and abandoned by competitors. Currently, only two devices are broadly used, which employ $4 \mathrm{MHz} \mathrm{CWD}$ and an angle of insonation of $45^{\circ}$ (CardioQ, Deltex Medical Ltd., Chichester, UK) or $5 \mathrm{MHz}$ PWD with an angle of insonation of $60^{\circ}$ (HemoSonic 100, Arrow International, Reading, PA, USA).

\section{TRANSLATING AORTIC BLOOD FLOW VELOCITY INTO HEMODYNAMIC PARAMETERS}

As erythrocytes pass the ultrasound beam in the descending aorta, blood flow velocity is calculated based on the Doppler equation. The systolic portion of the velocity-time envelope is typically triangular and the area under this curve $\left(\mathrm{cm} \mathrm{s}^{-1} \mathrm{~s}\right)$ represents the stroke distance $(\mathrm{cm})$, i.e. the distance that the blood column has moved forward in the aorta during systole (Figure 4). Stroke distance is proportional to stroke volume but the exact formula for the determination of stroke volume from stroke distance varies according to the device used. The
HemoSonic 100 device (Arrow International, Reading, PA, USA) provides real-time measurements of the aortic diameter via an integrated $10 \mathrm{MHz} \mathrm{M}$-mode ultrasound probe orientated at a $90^{\circ}$ angle to the central axis of the probe. Assuming a circular shape of the aorta, the aortic diameter is used to calculate aortic cross sectional area. By multiplying stroke distance $(\mathrm{cm})$ with aortic cross sectional area $\left(\mathrm{cm}^{2}\right)$, the descending aortic stroke volume $\left(\mathrm{cm}^{3}\right)$ can be determined (Figure 4). Blood flow in the descending aorta is only a fraction of total $\mathrm{CO}$, therefore a constant proportion of blood flow between the descending aorta $(\sim 70 \%)$ and the coronary and brachiocephalic arteries $(\sim 30 \%)$ is assumed to estimate systemic stroke volume. Instead of measuring the aortic diameter, the CardioQ device (Deltex Medical Ltd., Chichester, UK) estimates CO from a nomogram based on the patient's age, height and weight [46].

The aortic blood flow velocity-time envelope also allows the calculation of other advanced hemodynamic parameters which can be useful to estimate preload, afterload and myocardial contractility. The base of the triangular systolic portion of the plot represents the systolic ejection time (Fig. 4). This ejection time, frequently referred to as "flow time", depends on the heart rate. In analogy to correcting the QT interval of an ECG using Bazett's equation [47], flow time is corrected to one cardiac cycle per second ("flow time corrected", FTc) by dividing it by the square root of the cycle time. Acceleration of blood in the descending aorta during early systole corresponds to the upslope of the velocity-time plot, from which the mean acceleration can be determined. The peak of the triangle marks the peak blood 


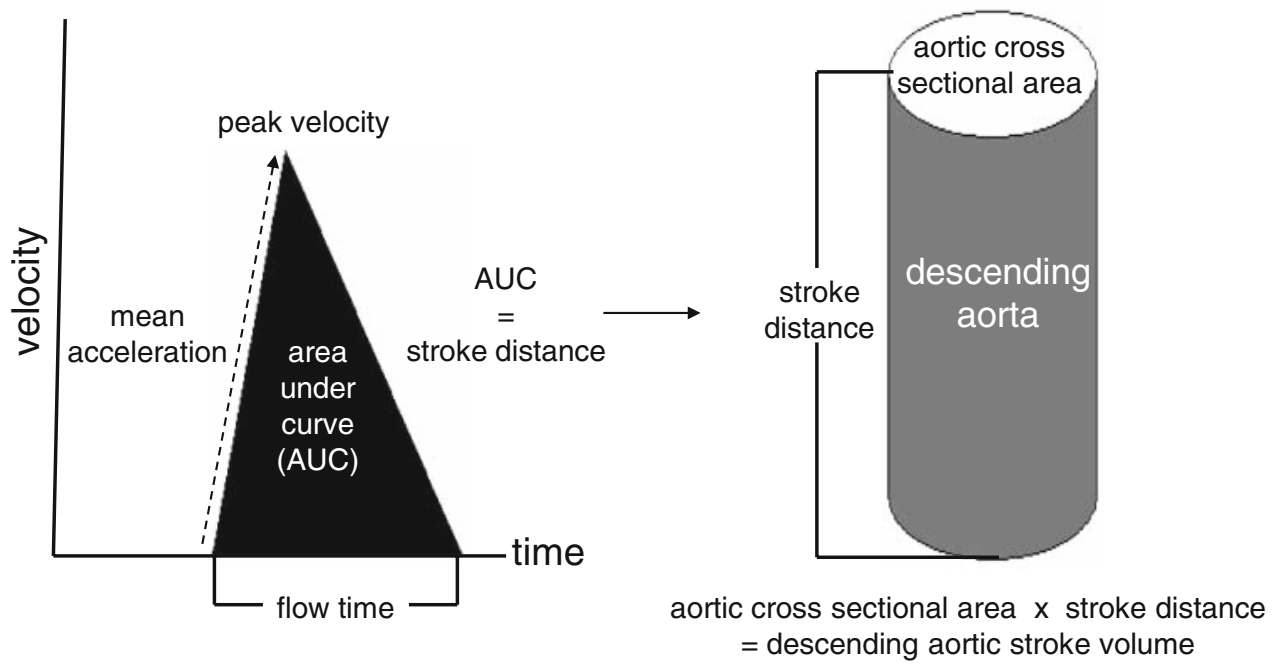

Fig. 4. Velocity-time plot and calculation of descending aortic blood flow. The systolic portion of the velocity-time plot is typically triangular and its base represents the flow time (= systolic ejection time). The upslope of the graph depicts the acceleration of blood and the peak of the waveform shows the peak velocity in the descending aorta. The area under the systolic portion of the curve (AUC) represents the stroke distance, i.e. the distance that the blood column has moved forward in the aorta during systole. The descending aortic stroke volume can be determined by multiplying the stroke distance with the aortic cross sectional area.

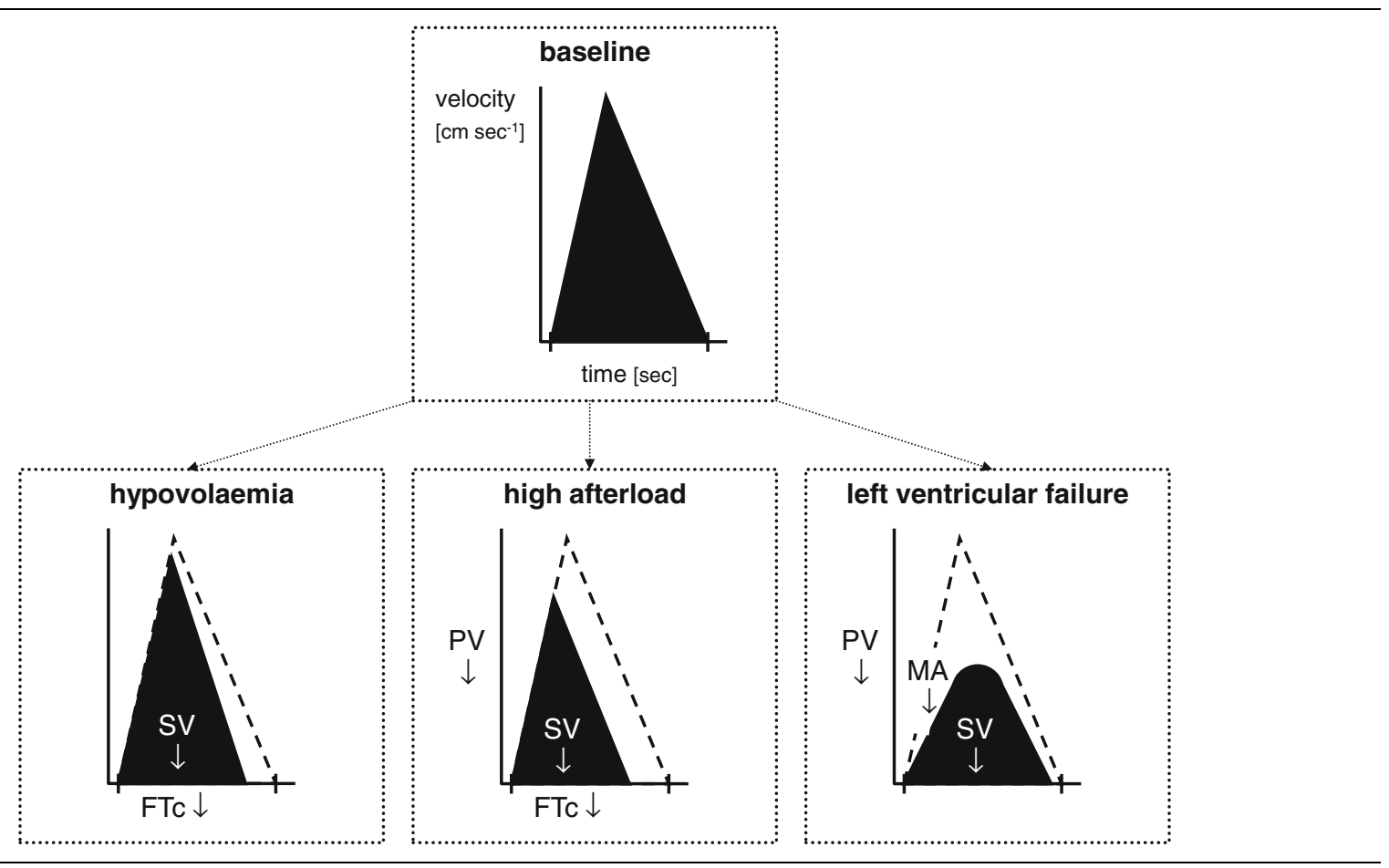

Fig. 5. Velocity-time waveforms of aortic blood flow under three hemodynamic conditions, which are all associated with a reduction in cardiac output but require different therapeutic approaches. Note that the waveform itself as well as the reported hemodynamic parameters can facilitate the differential diagnosis. $S V$ stroke volume, FTc flow time corrected, PV peak velocity, MA mean acceleration, $\uparrow$ and $\downarrow$ direction of change.

flow velocity during systole, followed by a down-slope which depicts deceleration of flow during later systole (Figure 4).
Reference values of these parameters have only poorly been established and changes in the parameters relative to their baseline value may be more informative than their 
absolute value. Since systole takes approximately onethird of the entire cardiac cycle, an FTc of about 330 milliseconds (ms) is generally considered normal [48], however, a shorter FTc of about 290 ms may be normal in young adults [49]. The peak velocity decreases with increasing age from $\sim 100$ to $130 \mathrm{~cm} \mathrm{~s}^{-1}$ at an age of 20 years to about $60-70 \mathrm{~cm} \mathrm{~s}^{-1}$ at 70 years [49, 50]. Ascending aortic blood flow measurements suggest that mean acceleration also decreases with increasing age [49].

The FTc primarily responds to changes in pre and afterload, while peak velocity and mean acceleration are predominantly considered markers of left ventricular contractility. However, it is important to realize that no single parameter is specific for preload, afterload or contractility and that changes in one parameter are in vivo accompanied by compensatory changes of other parameters. Only the combination of the different parameters and their response to dynamic cardiovascular events or therapeutic interventions can give a comprehensive picture of the hemodynamic situation. Typical responses of the TED key parameters stroke volume, FTc, peak velocity and mean acceleration to varying hemodynamic conditions have been reviewed previously $[20,21,51]$ and are summarized in Figure 5.

\section{CLINICAL USE}

Technically, the insertion of a TED probe is similar to the placement of a gastric tube [20]. Insertion depth is typically between 35 and $45 \mathrm{~cm}$ for adults, depending on the route of insertion (oral vs. nasal route). The probe is rotated until the ultrasound beam aligns with the descending aorta as confirmed by visualization of the typical aortic waveform and a characteristic pulsatile sound pattern. Optimal probe focus is accomplished by slight manipulations of the probe until the largest and sharpest possible waveform is found. The integrated $\mathrm{M}$-mode of the HemoSonic 100 device also allows direct visualisation of the aortic wall. Contraindications for the insertion of TED probes include any pathology which predisposes the patient to an increased risk of injury at the insertion site or esophagus, such as malformations, strictures, tumors, varices, esophagitis, or severe bleeding disorders [20].

TED-derived measurements of CO have been compared to reference methods, most often pulmonary artery catheter thermodilution techniques [38, 43, 45, 52-92]. The pooled median bias in the studies reporting BlandAltman analyses is moderate $\left(0.371 \mathrm{~min}^{-1}\right)$, however, with wide "95\% limits of agreement"-values (median $4.21 \mathrm{~min}^{-1}$ ) [20]. This demonstrates that TED does not systematically over or underestimate $\mathrm{CO}$, however, individual CO measurements obtained through TED may differ considerably from $\mathrm{CO}$ values derived by the thermodilution technique. The observed discrepancies between the absolute values measured with both techniques may in part be explained by the following factors. First, pulmonary artery catheter thermodilution techniques assess right ventricular output while TED measures aortic blood flow velocity, which is a function of left ventricular output. Right and leftventricular output are not necessarily identical, i.e. due to draining of venous blood from Thebesian and pulmonary veins also directly into the left heart. Second, although the thermodilution technique is considered the clinical "gold standard", it also has methodological limitations and does not necessarily reflect the "true" CO under all conditions [93, 94]. Third, some of the validation studies were performed under conditions in which basic assumptions of TED measurement concerning a constant diversion of blood flow were violated, e.g. by aortic cross clamping or epidural sympathicolysis [63, $73,82,85]$.

In clinical practice exact values are usually less relevant than information about changes in CO. The median correlation reported between TED and reference methods is 0.80 , suggesting that a high value obtained with one technique will likely be reflected by a high reading with the other technique and vice versa, and that the direction of changes in CO can be tracked by TED [20]. Indeed, numerous studies report that TED measurements accurately follow changes in CO over time $[43,54,55,60,63$, $74,78,80,82,83,85]$.

In critically ill patients, TED can be used for advanced hemodynamic management. However, up to now data to support its usefulness in guiding inotopic or vasoactive therapy in such patients is limited and the potential of TED to replace more invasive techniques in critical care units needs to be further determined. In contrast, the role of TED in optimizing perioperative volume replacement has been well characterized [11-19]. TED allows assessment of fluid responsiveness by monitoring changes in stroke volume secondary to fluid challenges, allowing individual titration of fluids to maximize $\mathrm{CO}$ while avoiding excessive fluid loading.

Clinical studies comparing TED guided protocols to conventional approaches of volume replacement (guided by clinical assessment and/or central venous pressure) conclusively report beneficial effects in the Doppleroptimized groups, including a reduced risk of postoperative morbidity and a shorter length of hospital or ICU stay [11-19]. In addition to fluid optimization, other clinical applications such as early detection of hemodynamic changes associated with transurethral resection syndrome have also been reported [95]. 


\section{TECHNICAL LIMITATIONS}

\section{Limitations in measurement of blood flow velocity}

Transesophageal Doppler devices basically measure only two parameters: the Doppler frequency shift and the elapsed time. Blood flow velocity is calculated from the frequency shift of ultrasound reflected by red blood cells under the assumption that all erythrocytes travel in the same direction and at the same speed. The pulsatile blood flow in combination with a complex aortic geometry including curvatures in multiple planes, tapering, branches, and distensible walls results in a complex threedimensional aortic flow pattern [96, 97]. Descending aortic blood flow is usually more or less laminar and shows a relative uniform velocity profile over the aortic cross section in healthy subjects [98]. However, the existence of skewed velocity profiles and rotational blood flow in the descending aorta has also been suggested [96]. Non-laminar flow might be expected in patients with pathology of the aorta or aortic valve, such as dissection, aneurysm, coarctation or valvular stenosis.

The angle of insonation must be known and remain constant for accurate velocity measurements. While this angle approximates the angle between the probe and the transducer in healthy persons, the above assumption may not hold true during surgical manipulations affecting the anatomic relationship between esophagus and aorta or in patients with altered thoracic anatomy, e.g. due to tumor mass, previous surgery or scoliosis.

Furthermore, the accuracy of velocity measurements principally depends on the chosen Doppler mode. CWD lacks depth resolution and therefore interrogates the blood flow in all vessels in the range of the ultrasound beam. Measurement of non-aortic blood flow, however, is negligible because there are no other major vessels in the range of the ultrasound beam when it is orientated from the oesophagus towards the descending aorta. PWD does allow axial resolution, enabling selective interrogation of aortic blood flow, however, at the cost of inaccuracy at high blood velocities [26, 27]. The maximum velocity which can be reliably measured depends on the pulse repetition frequency (PRF), which is for instance $\sim 12.4 \mathrm{kHz}$ for the HemoSonic 100 device. According to the Nyquist-Shannon sampling theorem, the maximum frequency shift that can be measured is one half of the PRF [26]. This maximum measurable frequency shift corresponds to a maximum detectable blood velocity of $\sim 190 \mathrm{~cm} \mathrm{~s}^{-1}$ when the frequency and angle of insonation of the HemoSonic 100 device are applied to the Doppler equation. Since this velocity considerably exceeds peak velocities normally observed in the aorta, we conclude that PWD as well as CWD are both similarly suitable for transesophageal determinations of aortic blood flow velocities despite their theoretical limitations.

\section{Limitations in the estimation of stroke volume and cardiac output}

After the aortic blood flow velocity has been determined, other hemodynamic parameters can be calculated. FTc, mean acceleration and stroke distance are calculated directly from the velocity-time-function and can therefore be regarded as relatively "robust" parameters. In contrast, calculations of stroke volume and $\mathrm{CO}$ require additional assumptions or estimations, introducing a potential for erroneous calculations. In fact, the need for a volumetric translation of TED data has been questioned due to these additional limitations [43].

The first drawback of calculating stroke volume is that the aortic cross sectional area needs to be known or estimated. One possibility is to measure the aortic diameter by M-mode ultrasound (for instance HemoSonic 100 device, Arrow International, Reading, PA, USA). This is complicated because the aortic diameter is not constant as ejected blood distends the aortic wall during systole [99, 100]. Moreover, the formula used to calculate aortic cross sectional area assumes a circular shape $\left(A=\pi r^{2}\right)$, however, the aorta is not a perfect circle. Neither is the aorta as cylindrical as depicted in Figure 4, rather it tapers from cranial to caudal giving it a slightly conical aspect. Another possibility is to circumvent these difficulties in measuring aortic diameter by using a nomogram to translate blood flow velocity to $\mathrm{CO}$ (for instance CardioQ, Deltex Medical Ltd., Chichester, UK) [46]. Nevertheless, a nomogram derived from average values in a population does not necessarily accurately predict individual values. Moreover, the nomogram does not account for changes in aortic diameter. Such changes may occur due to hemodynamic changes, e.g. blood loss or changes in blood pressure [100-102]. One study showed an inconsistent association between Doppler derived CO measurements and $\mathrm{CO}$ measured according to the Fick-principle in an experimental animal hemorrhage model [103]. The authors did not use the CardioQ nomogram but a calibration factor which was individually determined for each animal. In this study, TED often indicated an increase in $\mathrm{CO}$ in the face of ongoing blood loss, decreasing blood volume and arterial hypotension. The authors did not account for changes in the aortic diameter when calculating $\mathrm{CO}$ and conclude that especially these unaccounted changes in aortic diameter were responsible for the inconsistent and unpredictable values of $\mathrm{CO}$ they observed [103]. Users of TED should be aware that similar 
limitations may likely apply to every other calibration factor or nomogram which does not consider changes in aortic diameter.

Calculation of the stroke volume assumes a constant diversion of blood flow between supra-aortic vessels and the descending aorta. However, this proportion is not constant. Changes in vascular tone, e.g. due to general anesthetics, vasodilatation (e.g. due to sympathetic blockade during neuraxial anesthesia) as well as vasoconstriction (e.g. compensatory due to blood loss or mechanically during aortic cross clamping) may affect the distribution of CO [73, 104-106]. It should also be noted that in patients with aortic insufficiency a relevant portion of the systolic aortic blood flow does not contribute to organ perfusion as it regurgitates into the left ventricle during diastole.

Whenever the basic assumptions needed to translate the measured Doppler frequency shift into CO are violated, the absolute displayed value may likely be incorrect. However, trend monitoring of $\mathrm{CO}$ should theoretically be possible as long as the basic conditions remain unaltered. Indeed, as described earlier, the usefulness of TED as a trend-monitoring device has been confirmed by validation studies in various patient populations. However, it is important to realize that changes which affect the basic assumptions of the measurement technique, such as aortic clamping or unaccounted changes in aortic diameter due to acute blood loss, may result in changes of the displayed $\mathrm{CO}$ value which do not necessarily reflect the true changes associated with these events. This emphasizes the need to realize the limitations of TED monitoring and to consider all available parameters and clinical signs in the assessment of the patient.

\section{CONCLUSIONS}

Transesophageal Doppler devices interrogate the descending aortic blood flow and calculate aortic blood flow velocity based on the measured Doppler frequency shift. The resulting velocity-time plot allows estimations of $\mathrm{CO}$ and other advanced hemodynamic parameters, making TED a technology for continuous hemodynamic trend monitoring. While its role in the treatment of critically ill patients and its potential to replace more invasive techniques has not sufficiently been established, numerous studies support its use for guidance of perioperative volume therapy. TED-guided volume optimization has been shown to reduce perioperative complications and length of hospital stay, suggesting that TED may be a valuable supplement to current standard hemodynamic monitoring.

Correct interpretation of TED-derived data does not only require a thorough understanding of cardiovascular physiology, but also a profound knowledge of the technical basis of this method. Limitations may in part derive from inaccuracies in the determination of the blood flow velocity. However, especially the assumptions needed to translate descending aortic blood flow velocity to $\mathrm{CO}$ introduce a considerable potential for erroneous calculations. A simple ABCD scheme can be used to assess the validity of the displayed data:

Angle of insonation: known and constant?

Blood flow: laminar or turbulent?

Cross sectional area: unaccounted changes in aortic diameter?

Distribution of flow between supra-aortic vessels and descending aorta.

The user needs to be familiar with the inherent limitations to allow a rational and proper use of the technology.

Financial Support Departmental funding only.

\section{REFERENCES}

1. Karakitsos D, Labropoulos N, De GE, Patrianakos AP, Kouraklis G, Poularas J, Samonis G, Tsoutsos DA, Konstadoulakis MM, Karabinis A. Real-time ultrasound-guided catheterisation of the internal jugular vein: a prospective comparison with the landmark technique in critical care patients. Crit Care 2006; 10: R162.

2. Pirotte T. Ultrasound-guided vascular access in adults and children: beyond the internal jugular vein puncture. Acta Anaesthesiol Belg 2008; 59: 157-166.

3. Schober P, Krage R, Thöne D, Loer SA, Schwarte LA. Ultrasound-guided ankle block in stone man disease, fibrodysplasia ossificans progressiva. Anesth Analg 2009; 109: 988990.

4. Chin KJ, Chan V. Ultrasound-guided peripheral nerve blockade. Curr Opin Anaesthesiol 2008; 21: 624-631.

5. Rasulo FA, De PE, Lavinio A. Transcranial Doppler ultrasonography in intensive care. Eur J Anaesthesiol Suppl 2008; 42: 167-173.

6. Mostbeck GH, Zontsich T, Turetschek K. Ultrasound of the kidney: obstruction and medical diseases. Eur Radiol 2001; 11 : 1878-1889.

7. Correas JM, Claudon M, Tranquart F, Helenon AO. The kidney: imaging with microbubble contrast agents. Ultrasound Q 2006; 22: 53-66.

8. Urban G, Vergani P, Ghidini A, Tortoli P, Ricci S, Patrizio P, Paidas MJ. State of the art: non-invasive ultrasound assessment of the uteroplacental circulation. Semin Perinatol 2007; 31: $232-239$ 
9. Dietrich CF, Jedrzejczyk M, Ignee A. Sonographic assessment of splanchnic arteries and the bowel wall. Eur J Radiol 2007; 64: 202-212.

10. Chytra I, Pradl R, Bosman R, Pelnar P, Kasal E, Zidkova A. Esophageal Doppler-guided fluid management decreases blood lactate levels in multiple-trauma patients: a randomized controlled trial. Crit Care 2007; 11: R24.

11. Noblett SE, Snowden CP, Shenton BK, Horgan AF. Randomized clinical trial assessing the effect of Doppler-optimized fluid management on outcome after elective colorectal resection. Br J Surg 2006; 93: 1069-1076.

12. Wakeling HG, McFall MR, Jenkins CS, Woods WG, Miles WF, Barclay GR, Fleming SC. Intraoperative oesophageal Doppler guided fluid management shortens postoperative hospital stay after major bowel surgery. Br J Anaesth 2005; 95: 634-642.

13. McFall MR, Woods WG, Wakeling HG. The use of oesophageal Doppler cardiac output measurement to optimize fluid management during colorectal surgery. Eur J Anaesthesiol 2004; 21: 581-583.

14. McKendry M, McGloin H, Saberi D, Caudwell L, Brady AR, Singer M. Randomised controlled trial assessing the impact of a nurse delivered, flow monitored protocol for optimisation of circulatory status after cardiac surgery. BMJ 2004; 329: 258-261.

15. Conway DH, Mayall R, bdul-Latif MS, Gilligan S, Tackaberry C. Randomised controlled trial investigating the influence of intravenous fluid titration using oesophageal Doppler monitoring during bowel surgery. Anaesthesia 2002; 57: 845-849.

16. Gan TJ, Soppitt A, Maroof M, el-Moalem H, Robertson KM, Moretti E, Dwane P, Glass PS. Goal-directed intraoperative fluid administration reduces length of hospital stay after major surgery. Anesthesiology 2002; 97: 820-826.

17. Venn R, Steele A, Richardson P, Poloniecki J, Grounds M, Newman P. Randomized controlled trial to investigate influence of the fluid challenge on duration of hospital stay and perioperative morbidity in patients with hip fractures. Br J Anaesth 2002; 88: 65-71.

18. Sinclair S, James S, Singer M. Intraoperative intravascular volume optimisation and length of hospital stay after repair of proximal femoral fracture: randomised controlled trial. BMJ 1997; 315: 909-912.

19. Mythen MG, Webb AR. Perioperative plasma volume expansion reduces the incidence of gut mucosal hypoperfusion during cardiac surgery. Arch Surg 1995; 130: 423-429.

20. Schober P, Loer SA, Schwarte LA. Perioperative hemodynamic monitoring with transesophageal Doppler technology. Anesth Analg 2009; 109: 340-353.

21. Singer M. Oesophageal Doppler. Curr Opin Crit Care 2009; 15: 244-248.

22. Doppler JC. Über das farbige Licht der Doppelsterne und einiger anderer Gestirne des Himmels. Abhandlungen der königlichen böhmischen Gesellschaft der Wissenschaften 1842; 2: 465-482.

23. Buys Ballot C. Bedrog van het gehoororgaan in het bepalen van de hoogte van een waargenomen toon. Algemeen Muzikaal Tijdschrift van Nederland 1845; 2: 167-170.

24. Buys Ballot C. Akustische Versuche auf der Niederländischen Eisenbahn, nebst gelegentlichen Bemerkungen zur Theorie des
Herrn Professor Doppler. Annalen der Physik und Chemie 1845; 11: 321-351.

25. Shung KK, Sigelmann RA, Reid JM. Scattering of ultrasound by blood. IEEE Trans Biomed Eng 1976; 23: 460-467.

26. Taylor KJ, Holland S. Doppler US. Part I. Basic principles, instrumentation, and pitfalls. Radiology 1990; 174: 297-307.

27. Rubens DJ, Bhatt S, Nedelka S, Cullinan J. Doppler artifacts and pitfalls. Radiol Clin North Am 2006; 44: 805-835.

28. Nelson TR, Pretorius DH. The Doppler signal: where does it come from and what does it mean?. AJR Am J Roentgenol 1988; 151: 439-447.

29. Pellett AA, Kerut EK. The Doppler equation. Echocardiography 2004; 21: 197-198.

30. Franklin DL, Sschlegel W, Rushmer RF. Blood flow measured by Doppler frequency shift of back-scattered ultrasound. Science 1961; 134: 564-565.

31. Satomura S. Study of the flow patterns in peripheral arteries by ultrasonics. J Acoust Soc Jpn 1959; 15: 151-158.

32. Rushmer RF, Baker DW, Stegall HF. Transcutaneous Doppler flow detection as a nondestructive technique. J Appl Physiol 1966; 21: 554-566.

33. Stegall HF, Rushmer RF, Baker DW. A transcutaneous ultrasonic blood-velocity meter. J Appl Physiol 1966; 21: 707-711.

34. Light LH. Non-injurious ultrasonic technique for observing flow in the human aorta. Nature 1969; 224: 1119-1121.

35. Huntsman LL, Gams E, Johnson CC, Fairbanks E. Trancutaneous determination of aortic blood-flow velocities in man. Am Heart J 1975; 89: 605-612.

36. Side CD, Gosling RG. Non-surgical assessment of cardiac function. Nature 1971; 232: 335-336.

37. Histand MB, Wells MK, Reeves JT, Sodal IE, Adamson HP, Willson JT. Ultrasonic pulsed Doppler transoesophageal measurement of aortic haemodynamics in humans. Ultrasonics 1979; 17: 215-218.

38. Lefrant JY, Bruelle P, Aya AG, Saissi G, Dauzat M, de La Coussaye JE, Eledjam JJ. Training is required to improve the reliability of esophageal Doppler to measure cardiac output in critically ill patients. Intensive Care Med 1998; 24: 347-352.

39. Fourcade C, Cathignol D, Muchada R, Chapelon JYBui-Xuan B, Bouletreau P, Motin J. Validation de la débitmétrie aortique par capteur ultrasonore oesophagien dans la surveillance hémodynamique non sanglante. Agressologie 1980; 21: 121128 .

40. Tomlin PJ, Duck FA. Transoesophageal aortic velography in man. Can Anaesth Soc J 1975; 22: 561-571.

41. Wells MK, Histand MB, Reeves JT, Sodal IE, Adamson HP. Ultrasonic transesophageal measurement of hemodynamic parameters in humans. ISA Trans 1979; 18: 57-61.

42. Daigle RE, Miller CW, Histand MB, McLeod FD, Hokanson DE. Nontraumatic aortic blood flow sensing by use of an ultrasonic esophageal probe. J Appl Physiol 1975; 38: 1153-1160.

43. Singer M, Clarke J, Bennett ED. Continuous hemodynamic monitoring by esophageal Doppler. Crit Care Med 1989; 17: 447-452.

44. Olson RM, Cooke JP. A nondestructive ultrasonic technique to measure diameter and blood flow in arteries. IEEE Trans Biomed Eng 1974; 21: 168-171. 
45. Lavandier B, Cathignol D, Muchada R, Xuan BB, Motin J. Noninvasive aortic blood flow measurement using an intraesophageal probe. Ultrasound Med Biol 1985; 11: 451-460.

46. Singer M. ODM/CardioQ esophageal Doppler technology. Crit Care Med 2003; 31: 1888-1889.

47. Bazett HC. An analysis of the time-relations of electrocardiograms. Heart 1920; 7: 353-370.

48. Laupland KB, Bands CJ. Utility of esophageal Doppler as a minimally invasive hemodynamic monitor: a review. Can J Anaesth 2002; 49: 393-401.

49. Gardin JM, Davidson DM, Rohan MK, Butman S, Knoll M, Garcia R, Dubria S, Gardin SK, Henry WL. Relationship between age, body size, gender, and blood pressure and Doppler flow measurements in the aorta and pulmonary artery. Am Heart J 1987; 113: 101-109.

50. Mowat DH, Haites NE, Rawles JM. Aortic blood velocity measurement in healthy adults using a simple ultrasound technique. Cardiovasc Res 1983; 17: 75-80.

51. King SL, Lim MS. The use of the oesophageal Doppler monitor in the intensive care unit. Crit Care Resusc 2004; 6: $113-122$

52. Freund PR. Transesophageal Doppler scanning versus thermodilution during general anesthesia. An initial comparison of cardiac output techniques. Am J Surg 1987; 153: 490-494.

53. Moxon D, Pinder M, van Heerden PV, Parsons RW. Clinical evaluation of the HemoSonic monitor in cardiac surgical patients in the ICU. Anaesth Intensive Care 2003; 31: 408-411.

54. Tibby SM, Hatherill M, Murdoch IA. Use of transesophageal Doppler ultrasonography in ventilated pediatric patients: derivation of cardiac output. Crit Care Med 2000; 28: 2045-2050.

55. Penny JA, Anthony J, Shennan AH, De SM, Singer M. A comparison of hemodynamic data derived by pulmonary artery flotation catheter and the esophageal Doppler monitor in preeclampsia. Am J Obstet Gynecol 2000; 183: 658-661.

56. Krishnamurthy B, McMurray TJ, McClean E. The perioperative use of the oesophageal Doppler monitor in patients undergoing coronary artery revascularisation. A comparison with the continuous cardiac output monitor. Anaesthesia 1997; 52: 624-629.

57. Su NY, Huang CJ, Tsai P, Hsu YW, Hung YC, Cheng CR. Cardiac output measurement during cardiac surgery: esophageal Doppler versus pulmonary artery catheter. Acta Anaesthesiol Sin 2002; 40: 127-133.

58. Perrino AC, Fleming J, LaMantia KR. Transesophageal Doppler ultrasonography: evidence for improved cardiac output monitoring. Anesth Analg 1990; 71: 651-657.

59. Singer M, Bennett ED. Noninvasive optimization of left ventricular filling using esophageal Doppler. Crit Care Med 1991; 19: 1132-1137.

60. Cariou A, Monchi M, Joly LM, Bellenfant F, Claessens YE, Thebert D, Brunet F, Dhainaut JF. Noninvasive cardiac output monitoring by aortic blood flow determination: evaluation of the Sometec Dynemo-3000 system. Crit Care Med 1998; 26: 2066-2072.

61. Singer M, Bennett D. Optimisation of positive end expiratory pressure for maximal delivery of oxygen to tissues using oesophageal Doppler ultrasonography. BMJ 1989; 298: 13501353.

62. Knirsch W, Kretschmar O, Tomaske M, Stutz K, Nagdyman N, Balmer C, Schmitz A, Berger F, Bauersfeld U, Weiss M.
Comparison of cardiac output measurement using the CardioQP oesophageal Doppler with cardiac output measurement using thermodilution technique in children during heart catheterisation. Anaesthesia 2008; 63: 851-855.

63. Lafanechere A, Albaladejo P, Raux M, Geeraerts T, Bocquet R, Wernet A, Castier Y, Marty J. Cardiac output measurement during infrarenal aortic surgery: echo-esophageal Doppler versus thermodilution catheter. J Cardiothorac Vasc Anesth 2006; 20: 26-30.

64. Sharma J, Bhise M, Singh A, Mehta Y, Trehan N. Hemodynamic measurements after cardiac surgery: transesophageal Doppler versus pulmonary artery catheter. J Cardiothorac Vasc Anesth 2005; 19: 746-750.

65. Collins S, Girard F, Boudreault D, Chouinard P, Normandin L, Couture P, Caron MJ, Ruel M. Esophageal Doppler and thermodilution are not interchangeable for determination of cardiac output. Can J Anaesth 2005; 52: 978-985.

66. Bein B, Worthmann F, Tonner PH, Paris A, Steinfath M, Hedderich J, Scholz J. Comparison of esophageal Doppler, pulse contour analysis, and real-time pulmonary artery thermodilution for the continuous measurement of cardiac output. J Cardiothorac Vasc Anesth 2004; 18: 185-189.

67. Decoene C, Modine T, Al-Ruzzeh S, Athanasiou T, Fawzi D, Azzaoui R, Pol A, Fayad G. Analysis of thoracic aortic blood flow during off-pump coronary artery bypass surgery. Eur J Cardiothorac Surg 2004; 25: 26-34.

68. Kim K, Kwok I, Chang H, Han T. Comparison of cardiac outputs of major burn patients undergoing extensive early escharectomy: esophageal Doppler monitor versus thermodilution pulmonary artery catheter. J Trauma 2004; 57: 10131017.

69. Hullett B, Gibbs N, Weightman W, Thackray M, Newman M. A comparison of CardioQ and thermodilution cardiac output during off-pump coronary artery surgery. J Cardiothorac Vasc Anesth 2003; 17: 728-732.

70. Jaeggi P, Hofer CK, Klaghofer R, Fodor P, Genoni M, Zollinger A. Measurement of cardiac output after cardiac surgery by a new transesophageal Doppler device. J Cardiothorac Vasc Anesth 2003; 17: 217-220.

71. Seoudi HM, Perkal MF, Hanrahan A, Angood PB. The esophageal Doppler monitor in mechanically ventilated surgical patients: does it work?. J Trauma 2003; 55: 720-725.

72. Roeck M, Jakob SM, Boehlen T, Brander L, Knuesel R, Takala J. Change in stroke volume in response to fluid challenge: assessment using esophageal Doppler. Intensive Care Med 2003; 29: 1729-1735.

73. Leather HA, Wouters PF. Oesophageal Doppler monitoring overestimates cardiac output during lumbar epidural anaesthesia. Br J Anaesth 2001; 86: 794-797.

74. Odenstedt H, Aneman A, Oi Y, Svensson M, Stenqvist O, Lundin S. Descending aortic blood flow and cardiac output: a clinical and experimental study of continuous oesophageal echo-Doppler flowmetry. Acta Anaesthesiol Scand 2001; 45: 180-187.

75. DiCorte CJ, Latham P, Greilich PE, Cooley MV, Grayburn PA, Jessen ME. Esophageal Doppler monitor determinations of cardiac output and preload during cardiac operations. Ann Thorac Surg 2000; 69: 1782-1786.

76. Baillard C, Cohen Y, Fosse JP, Karoubi P, Hoang P, Cupa M. Haemodynamic measurements (continuous cardiac output and 
systemic vascular resistance) in critically ill patients: transoesophageal Doppler versus continuous thermodilution. Anaesth Intensive Care 1999; 27: 33-37.

77. Madan AK, UyBarreta VV, iabadi-Wahle S, Jesperson R, Hartz RS, Flint LM, Steinberg SM. Esophageal Doppler ultrasound monitor versus pulmonary artery catheter in the hemodynamic management of critically ill surgical patients. J Trauma 1999; 46: 607-611.

78. Bernardin G, Tiger F, Fouche R, Mattei M. Continuous noninvasive measurement of aortic blood flow in critically ill patients with a new esophageal echo-Doppler system. J Crit Care 1998; 13: 177-183.

79. Colbert S, O’Hanlon DM, Duranteau J, Ecoffey C. Cardiac output during liver transplantation. Can J Anaesth 1998; 45: 133-138.

80. Valtier B, Cholley BP, Belot JP, de La Coussaye JE, Mateo J, Payen DM. Noninvasive monitoring of cardiac output in critically ill patients using transesophageal Doppler. Am J Respir Crit Care Med 1998; 158: 77-83.

81. Keyl C, Rodig G, Lemberger P, Hobbhahn J. A comparison of the use of transoesophageal Doppler and thermodilution techniques for cardiac output determination. Eur J Anaesthesiol 1996; 13: 136-142.

82. Klotz KF, Klingsiek S, Singer M, Wenk H, Eleftheriadis S, Kuppe H, Schmucker P. Continuous measurement of cardiac output during aortic cross-clamping by the oesophageal Doppler monitor ODM 1. Br J Anaesth 1995; 74: 655-660.

83. Murdoch IA, Marsh MJ, Tibby SM, McLuckie A. Continuous haemodynamic monitoring in children: use of transoesophageal Doppler. Acta Paediatr 1995; 84: 761-764.

84. Schmid ER, Spahn DR, Tornic M. Reliability of a new generation transesophageal Doppler device for cardiac output monitoring. Anesth Analg 1993; 77: 971-979.

85. Perrino AC, Fleming J, LaMantia KR. Transesophageal Doppler cardiac output monitoring: performance during aortic reconstructive surgery. Anesth Analg 1991; 73: 705-710.

86. Stein MS, Barratt SM, Purcell GJ. Intraoperative assessment of the Lawrence 3000 Doppler cardiac output monitor. Anaesth Intensive Care 1991; 19: 251-255.

87. Spahn DR, Schmid ER, Tornic M, Jenni R, von Segesser L, Turina M, Baetscher A. Noninvasive versus invasive assessment of cardiac output after cardiac surgery: clinical validation. J Cardiothorac Anesth 1990; 4: 46-59.

88. Kumar A, Minagoe S, Thangathurai D, Mikhail M, Novia D, Viljoen JF, Rahimtoola SH, Chandraratna PA. Noninvasive measurement of cardiac output during surgery using a new continuous-wave Doppler esophageal probe. Am J Cardiol 1989; 64: 793-798.

89. Ueda M, Yokota S, Nakata F, Kaseno S, Sakuraya N, Kemmotsu O. Clinical evaluation of esophageal doppler cardiac output measurement during general anesthesia. J Anesth 1989; 3: 178-182.

90. Siegel LC, Shafer SL, Martinez GM, Ream AK, Scott JC. Simultaneous measurements of cardiac output by thermodilu- tion, esophageal Doppler, and electrical impedance in anesthetized patients. J Cardiothorac Anesth 1988; 2: 590-595.

91. Mark JB, Steinbrook RA, Gugino LD, Maddi R, Hartwell B, Shemin R, DiSesa V, Rida WN. Continuous noninvasive monitoring of cardiac output with esophageal Doppler ultrasound during cardiac surgery. Anesth Analg 1986; 65: 10131020.

92. Iregui MG, Prentice D, Sherman G, Schallom L, Sona C, Kollef MH. Physicians' estimates of cardiac index and intravascular volume based on clinical assessment versus transesophageal Doppler measurements obtained by critical care nurses. Am J Crit Care 2003; 12: 336-342.

93. Gomez CM, Palazzo MG. Pulmonary artery catheterization in anaesthesia and intensive care. Br J Anaesth 1998; 81: 945-956.

94. Robin E, Costecalde M, Lebuffe G, Vallet B. Clinical relevance of data from the pulmonary artery catheter. Crit Care 2006; 10(Suppl 3): S3.

95. Schober P, Meuleman EJ, Boer C, Loer SA, Schwarte LA. Transurethral resection syndrome detected and managed using transesophageal Doppler. Anesth Analg 2008; 107: 921-925.

96. Chandran KB. Flow dynamics in the human aorta. J Biomech Eng 1993; 115: 611-616.

97. Bogren HG, Buonocore MH. Complex flow patterns in the great vessels: a review. Int J Card Imaging 1999; 15: 105-113.

98. Klipstein RH, Firmin DN, Underwood SR, Rees RS, Longmore DB. Blood flow patterns in the human aorta studied by magnetic resonance. Br Heart J 1987; 58: 316-323.

99. Munoz HR, Sacco CM. Cardiac mechanical energy and effects on the arterial tree. J Cardiothorac Vasc Anesth 1997; 11: 289-298.

100. Greenfield JC, Patel DJ. Relation between pressure and diameter in the ascending aorta of man. Circ Res 1962; 10: 778-781.

101. Lnne T, Stale H, Bengtsson H, Gustafsson D, Bergqvist D, Sonesson B, Lecerof H, Dahl P. Noninvasive measurement of diameter changes in the distal abdominal aorta in man. Ultrasound Med Biol 1992; 18: 451-457.

102. Monnet X, Chemla D, Osman D, Anguel N, Richard C, Pinsky MR, Teboul JL. Measuring aortic diameter improves accuracy of esophageal Doppler in assessing fluid responsiveness. Crit Care Med 2007; 35: 477-482.

103. Kamal GD, Symreng T, Starr J. Inconsistent esophageal Doppler cardiac output during acute blood loss. Anesthesiology 1990; 72: 95-99.

104. Oyama M, McNamara JJ, Suehiro GT, Suehiro A, Sue-Ako K. The effects of thoracic aortic cross-clamping and declamping on visceral organ blood flow. Ann Surg 1983; 197: 459-463.

105. Schenk WG, Camp FA, Kjartansson KB, Pollock L. Hemorrhage without hypotension: an experimental study of aortic flow redistribution following minor hemorrhage. Ann Surg 1964; 160: 7-13.

106. Dumans-Nizard V, Nizard J, Payen D, Cholley BP. Redistribution of cardiac output during hemorrhagic shock in sheep. Crit Care Med 2006; 34: 1147-1151. 